\title{
Анодное окисление слоев кремний-на-изоляторе, созданных методом водородного переноса
}

\author{
(С) И.Е. Тысченко, И.В. Попов, Е.В. Спесивцев
}

Институт фризики полупроводников им. А.В. Ржанова Сибирского отделения Российской академии наук, 630090 Новосибирск, Россия

E-mail: tys@isp.nsc.ru

(Получена 14 мая 2018 г. Принята к печати 21 мая 2018 г.)

Изучена скорость анодного окисления пленок кремний-на-изоляторе (КНИ), созданных методом водородного переноса, как функция температуры последующего отжига. Установлено, что скорость окисления перенесенных пленок КНИ в 5 раз меньше по сравнению со скоростью окисления образцов монокристаллического объемного кремния. Скорость окисления растет по мере отжига образцов в интервале температур $700-1100^{\circ} \mathrm{C}$, а также с глубиной по мере поэтапного удаления анодно-окисленных слоев. Полученные результаты объясняются увеличением эффективности анодного тока и взаимодействия атомов кислорода и кремния соответственно за счет отжига дефектов и выхода водорода из связанного состояния. Обнаружено образование водородных пузырей в приповерхностной области кремния за счет диффузии водорода, высвобождающегося в процессе реакции окисления, к микропорам в слое КНИ.

DOI: 10.21883/FTP.2019.02.47109.8908

\section{1. Введение}

Метод анодного окисления слоев кремния давно зарекомендовал себя как низкотемпературный метод создания пленок оксида кремния толщиной от нескольких единиц до нескольких сотен $\AA$ [1-5]. Преимущества этого метода перед термическим окислением обусловлены тем, что процесс анодного окисления протекает при комнатной температуре и в нем участвует лишь тонкий приповерхностный слой образца. Точность и воспроизводимость метода позволяют широко использовать его и для прецизионного удаления слоев кремния. Несмотря на то что метод анодного окисления уже несколько десятков лет успешно используется экспериментаторами, возможности его использования для утончения слоев „кремний-на-изоляторе“ (КНИ) вплоть до недавнего времени были неизученными. С другой стороны, процесс окисления слоев КНИ может сильно отличаться от окисления образцов объемного кремния. В работе [6] было показано, что уменьшение толщины пленки отсеченного кремния до величин $<100 \mathrm{Hм}$ сопровождается резким снижением скорости анодного окисления. Для пленок КНИ толщиной $\leq 10$ нм предельная толщина окисленного слоя кремния составляет $\sim 0.4$ нм. Наблюдаемый эффект был объяснен увеличением сопротивления рабочего слоя кремния, ограничивающего поток дырок в плоскости пленки КНИ и, как следствие, количества катионов кремния, поступающих к границе $\mathrm{SiO}_{2}$ /электролит. Это в свою очередь является причиной снижения эффективности анодного тока.

Согласно имеющимся в литературе данным, процесс анодного окисления имплантированного кремния зависит от параметров ионного облучения. В работе [7] было установлено, что после имплантации слоев $\mathrm{Si}$ $p$-типа проводимости ионами $\mathrm{P}^{+}$с энергией 30 кэВ, дозой $\sim 5 \cdot 10^{14} \mathrm{~cm}^{-2}$ наблюдается увеличение толщины окисленного слоя в области максимума распределения атомов фосфора по сравнению со слоями, окисленными в областях с меньшим содержанием фосфора. При меньших дозах ионов $\mathrm{P}^{+}$этот эффект не наблюдался. Аналогичные результаты были получены и для пленок кремния $n$-типа проводимости, облученных ионами $\mathrm{B}^{+} \mathrm{c}$ энергией 30 кэВ, дозой $\sim 10^{15} \mathrm{~cm}^{-2}$. Увеличение толщины окисленного слоя в области максимума распределения внедренных атомов бора по сравнению со слоями, не облученными ионами или облученными меньшими дозами, составляло $20 \%$ [7]. Поскольку ионы $\mathrm{P}^{+}$почти в 3 раза тяжелее ионов $\mathrm{B}^{+}$, а эффект увеличения скорости анодного окисления наблюдается при одних и тех же дозах облучения, то полученные результаты указывают на то, что скорость окисления в данном случае определялась не столько структурным разупорядочением, сколько проводимостью окисляемых слоев.

Пленки кремния на изоляторе, созданные методом водородного переноса, содержат в приповерхностном слое как дефекты структуры, так и высокую концентрацию водорода, которая может достигать $\geq 10$ ат\%. При этом избыточный водород может находиться как в связанном состоянии, так и в молекулярном виде, заполняя вакансионные микропоры, формирующиеся в результате имплантации больших доз ионов водорода. Обычно для удаления нарушенного водородсодержащего слоя используют термическое окисление в атмосфере влажного кислорода. Однако существует целый ряд задач, когда использование высокотемпературного окисления невозможно - например, в случае переноса гетероструктур с сильно различающимися коэффициентами термического расширения или слоев кремния, содержащих готовые элементы интегральных схем. В этих случаях использование метода анодного окисления весьма актуально. Однако наличие связанного водорода в слоях кремния может препятствовать образованию катионов кремния, 
поступающих к границе $\mathrm{SiO}_{2}$ /электролит. До настоящего времени этот вопрос в литературе оставался неизученным. Поэтому целью настоящей работы является изучение скорости анодного окисления слоев кремнийна-изоляторе, созданных методом водородного переноса.

\section{2. Методика экспериментов}

КНИ структуры были изготовлены на линейке КНИ и КНС (кремний-на-сапфире) структур в Институте физики полупроводников СО РАН методом водородного переноса, описанным в работе [8]. В качестве исходного материала использовались две монокристаллические пластины кремния марки КЭФ 10-20 с ориентацией (100) производства компании WRS (США). На первой пластине был выращен слой $\mathrm{SiO}_{2}$ толщиной 320 нм. Во вторую пластину была проведена имплантация ионов $\mathrm{H}_{2}^{+}$с энергий 120 кэВ дозой $2.7 \cdot 10^{16} \mathrm{~cm}^{-2}$. Затем со второй пластины на слой $\mathrm{SiO}_{2}$ первой пластины была перенесена пленка кремния, толщина которой составила около 540 нм. Расслоение пленки кремния по имплантированному ионами водорода слою проводилось при температуре $450^{\circ} \mathrm{C}$. Исследуемые образцы вырезались в форме прямоугольника площадью $\sim 1 \mathrm{~cm}^{2}$. Анодное окисление проводилось в ячейке, в которой анодом являлся окисляемый образец КНИ, а катодом - пластина высокоомного кремния. Подробно условия анодного окисления описаны в работе [6]. Окисление проводилось в гальваностатическом режиме, плотность тока составляла $8 \mathrm{MA} / \mathrm{cm}^{2}$. Окисление проводилось при комнатной температуре. Окисленные слои последовательно удалялись в растворе $\mathrm{HF}: \mathrm{H}_{2} \mathrm{O}=1: 50$. Отжиг образцов проводился в печи при температурах $600-1100^{\circ} \mathrm{C}$, в течение 15 мин, в потоке $\mathrm{N}_{2}$. Контроль толщины окисленных слоев осуществлялся методом спектральной эллипсометрии на эллипсометре „Эллипс-1891“, изготовленном в Институте физики полупроводников СО РАН. В качестве источника света использовалась ксеноновая лампа мощностью $75 \mathrm{BT}$ с монохроматором. Измерения проводились в спектральном диапазоне 250-1000 нм. Световое пятно имело форму эллипса $1 \times 3$ мм. Измерения проводились в центральной части образца, где толщина растущего окисла была однородной. Изображения поверхности образцов были получены с помощью микроскопа Carl Zeiss Axio Imager.M2m. Фотографирование проводилось в отраженном свете в режиме дифференциально-интерференционного контраста с круговой поляризацией света при увеличении $\times 100$ и $\times 500$.

\section{3. Результаты и обсуждение}

На рис. 1 представлено пространственное распределение атомов водорода и радиационных дефектов в кремнии после имплантации ионов $\mathrm{H}^{+}$с энергией 120 кэВ, дозой $2.7 \cdot 10^{16} \mathrm{~cm}^{-2}$, рассчитанные методом Monte Carlo

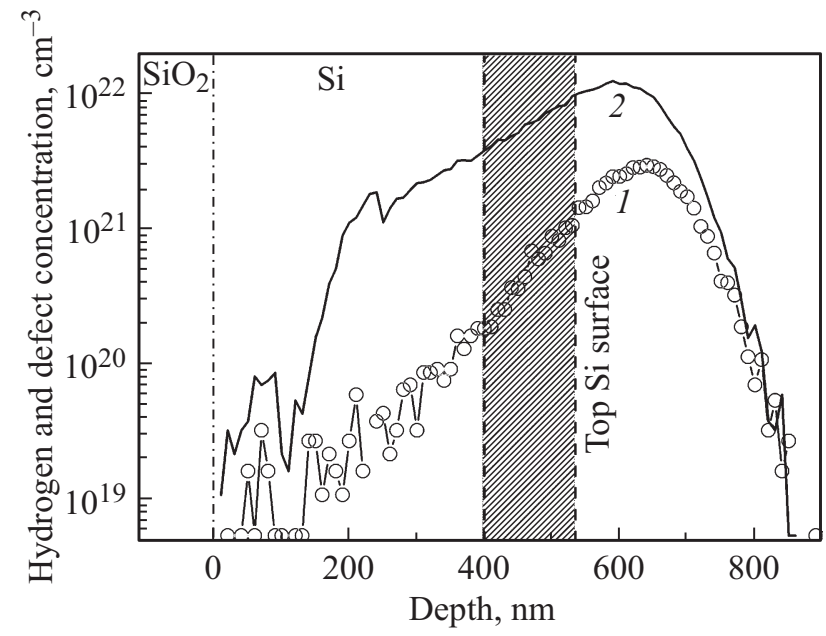

Рис. 1. Пространственное распределение атомов водорода (1) и первично смещенных атомов (2) в пленках кремния, имплантированных ионами $\mathrm{H}^{+} \mathrm{c}$ энергией 120 кэВ, дозой $2.7 \cdot 10^{16} \mathrm{~cm}^{-2}$, рассчитанное с использованием стандартной программы SRIM. Заштрихованная область показывает слой кремния от поверхности перенесенной пленки вглубь образца, в которой проводилось послойное анодное окисление.

с использованием стандартной программы SRIM [9]. На рисунке также показана граница, соответствующая поверхности перенесенного слоя кремния, и условная граница раздела между слоем КНИ и захороненным оксидом кремния. Штриховкой показана область кремния, в которой изучался процесс анодного окисления. Из рисунка видно, что в исследованной области концентрация атомов водорода плавно спадает от $\sim 10^{21}$ до $\sim 10^{20} \mathrm{~cm}^{-3}$. Концентрация упругосмещенных атомов на этом же интервале глубин изменяется лишь в 2 раза.

Толщина анодного окисла, нормированная на величину падающего на слое $\mathrm{SiO}_{2}$ напряжения для указанных значений тока, при окислении образцов монокристаллического кремния составляет $\sim 0.22 \mathrm{HM} / \mathrm{B}$, в то время как для пленок КНИ, окисляемых сразу после водородного переноса, это значение падает до $\sim 0.04 \mathrm{HM} / \mathrm{B}$. Толщина анодного окисла в этом случае оказывается в $\sim 5$ раз меньше, чем в случае окисления объемного монокристаллического кремния. С целью выяснения природы наблюдаемого эффекта мы исследовали скорость анодного окисления пленок КНИ в зависимости от температуры последующего отжига. Эти данные представлены на рис. 2. Из рисунка видно, что скорость окисления перенесенного слоя КНИ практически не изменяется с температурой отжига вплоть до температуры $T=1100^{\circ} \mathrm{C}$. Лишь отжиг при температуре $1100^{\circ} \mathrm{C}$ приводит к резкому увеличению скорости окисления, практически до значений, соответствующих скорости окисления объемного монокристаллического кремния.

На рис. 3 представлено изменение толщины окисленного слоя кремния образцов КНИ, отожженных при температурах 700, 900 и $1000^{\circ} \mathrm{C}$, в зависимости 


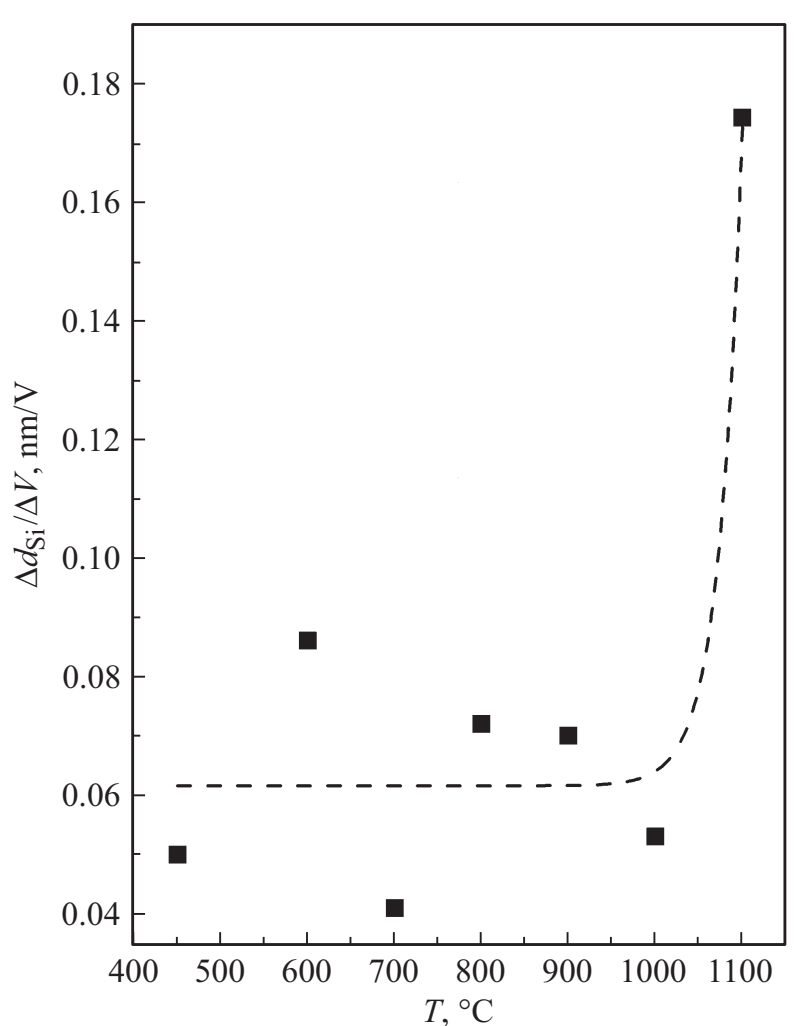

Рис. 2. Зависимость толщины окисленного кремния $\Delta d_{\mathrm{Si}}$, нормированного на величину напряжения $\Delta V$, падающего на слое $\mathrm{SiO}_{2}$, от температуры отжига образцов.

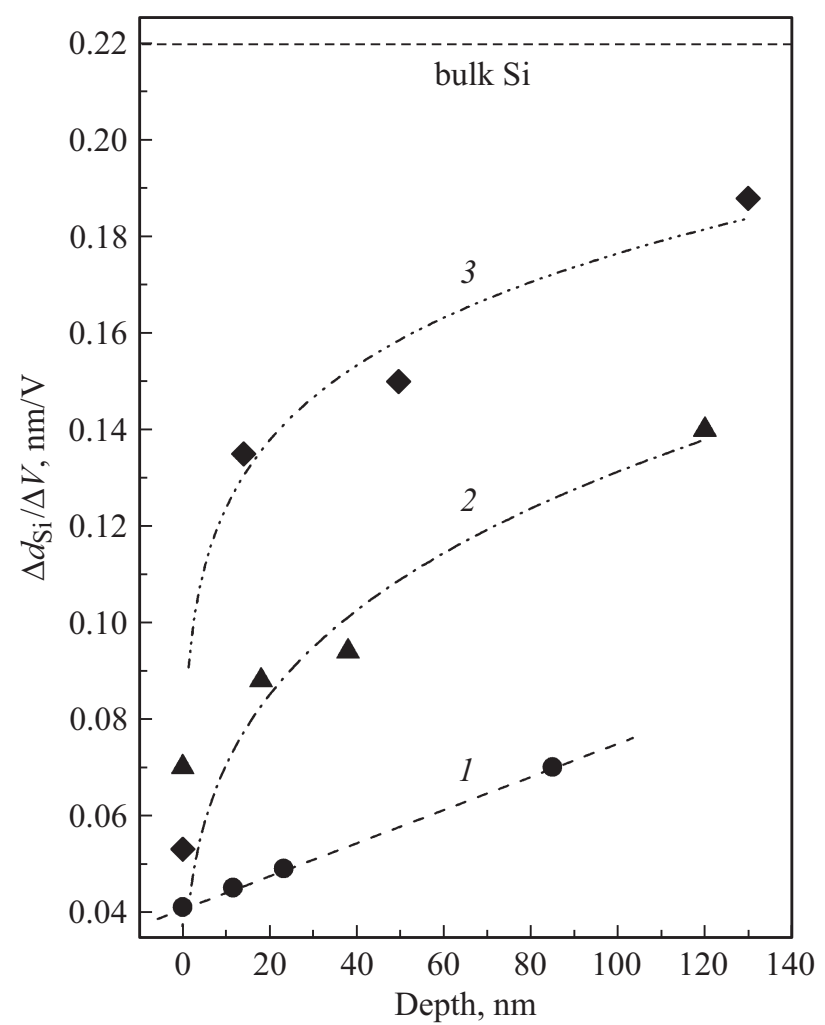

Рис. 3. Изменение толщины окисленного слоя кремния образцов КНИ, отожженных при температурах 700,900 и $1000^{\circ} \mathrm{C}$, в зависимости от расстояния от исходной поверхности слоя кремния. от толщины удаленного сверху слоя $\mathrm{Si}$. Из рисунка видно, что после отжига образцов КНИ при температуре $700^{\circ} \mathrm{C}$ изменение скорости окисления остается низкой, но медленно растет с расстоянием в глубь образца, увеличиваясь в 2 раза после удаления верхнего слоя толщиной $\sim 120 \mathrm{Hм}$. Увеличение температуры отжига до $900^{\circ} \mathrm{C}$ сопровождается ростом изменения толщины окисленного слоя, приходящегося на единицу падающего на окисле напряжения, в 2 раза уже на расстоянии $\sim 20$ нм от поверхности образца. После удаления верхнего слоя кремния толщиной $\sim(40-50)$ нм, наклон зависимости становится таким же, как и в случае образцов, отожженных при температуре $700^{\circ} \mathrm{C}$. Аналогичный эффект наблюдается и в образцах, отожженных при температуре $1000^{\circ} \mathrm{C}$. При росте абсолютного значения скорости окисления наклон ее зависимости от глубины в слое кремния сохраняется.

На рис. 4 представлены изображения поверхностей образца КНИ до (рис. 4,a) и после отжига при температуpe $1000^{\circ} \mathrm{C}$ (рис. $4, b$ ), а также после анодного окисления неотожженного образца на суммарную глубину $\sim 50$ нм по кремнию (рис. 4,c). Из рисунка видно, что сразу после водородного переноса поверхность образца является ровной и не содержит никаких микронеоднородностей или пузырей. После отжига на поверхности образцов наблюдалось появление микрочастиц со средними размерами около $\sim 1$ мкм, природа которых, скорее всего, связана с загрязнениями, осевшими на поверхности при переносе образца в печь при комнатных условиях. Формирования пузырей в этом случае также не происходило (рис. 4, $b$ ). После анодного окисления неотожженных образцов на их поверхности наблюдаются мелкие водородные пузыри, размеры которых увеличиваются по мере роста длительностей окисления от 20 до $\sim 40$ мкм.

Наблюдаемые эффекты могут быть объяснены с точки зрения взаимодействия водорода, выделяемого в процессе химической реакции при анодном окислении кремния, с вакансионными микропорами, залегающими вблизи поверхности перенесенного слоя кремния. Согласно данным, приведенным на рис. 1 и 4, количества имплантированного водорода, запасенного в приповерхностном слое перенесенной пленки кремния, недостаточно для достижения критического значения давления газа в микропоре и формирования при последующем отжиге водородного пузыря [10]. В общем виде реакция окисления Si на аноде имеет следующий вид:

$$
\mathrm{Si}+2 \mathrm{H}_{2} \mathrm{O}+4 h^{+} \rightarrow \mathrm{SiO}_{2}+4 \mathrm{H}^{+},
$$

где $h^{+}$- положительно заряженные носители заряда (дырки). Как видно из выражения (1), одним из продуктов реакции окисления является водород. Обычно атомы водорода при окислении образуют молекулу $\mathrm{H}_{2}$ и собираются в виде водородных пузырей на поверхности образца, препятствуя тем самым взаимодействию кислорода и кремния. С целью устранения этого влияния процесс анодного окисления проводят при непрерывном 

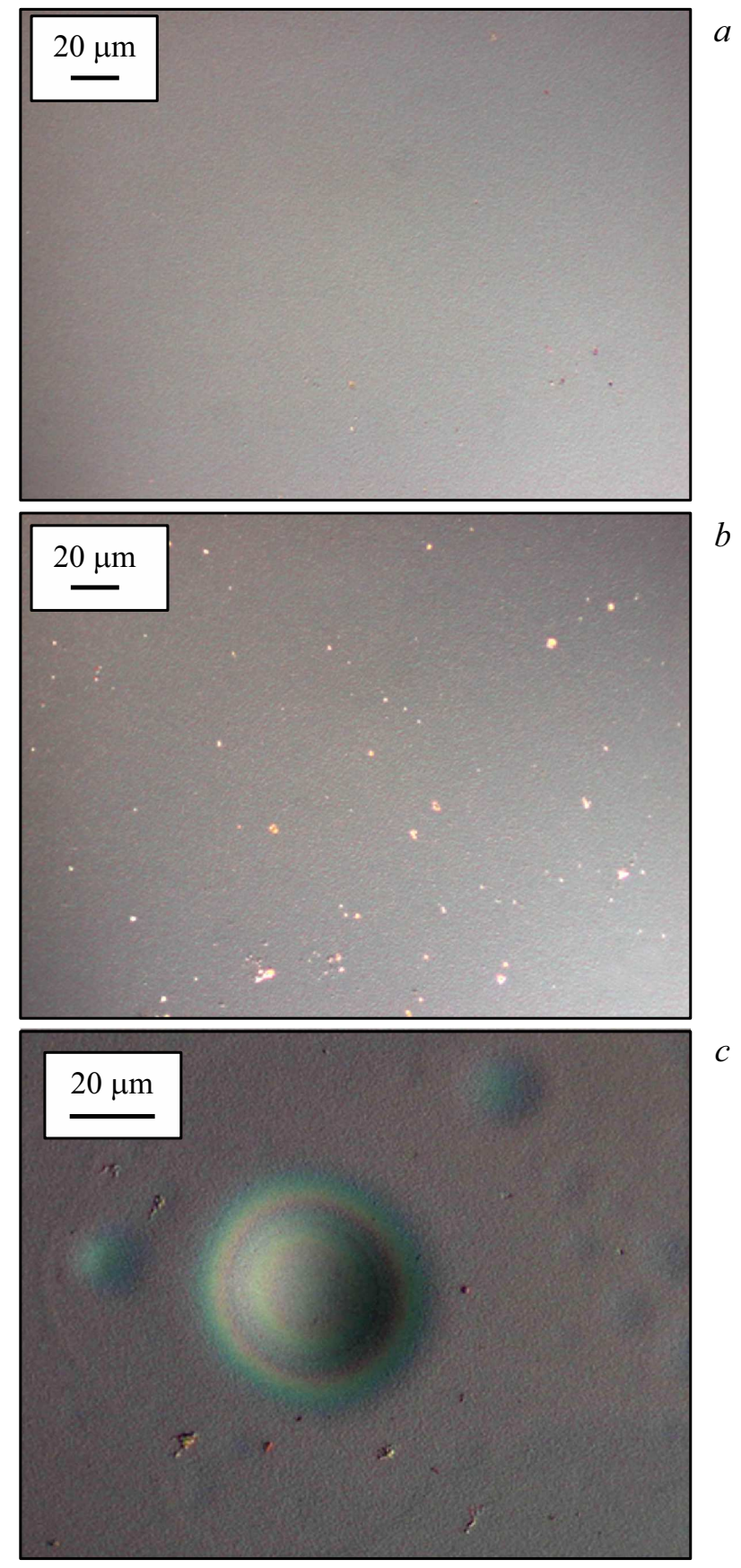

Рис. 4. Изображения поверхности неокисленных образцов КНИ до $(a)$ и после отжига при температуре $1000^{\circ} \mathrm{C}(b)$, а также после анодного окисления неотожженного образца на глубину около 50 нм $(c)$.

перемешивании раствора электролита. В наших экспериментах рост водородных пузырей в приповерхностном слое кремния при анодном окислении свидетельствует в пользу диффузии водорода с поверхности в глубь кремния к вакансионным микропорам, формирующимся в имплантированном слое за счет генерации точечных дефектов и их стабилизации в результате образования связей $\mathrm{Si}-\mathrm{H}$. При анодном окислении этот процесс облегчен растущим окислом. Коэффициент диффузии водорода в $\mathrm{SiO}_{2}$ хорошо известен $[11,12]$. Для атомарного водорода его температурная зависимость описывается выражением [11]

$$
D_{\mathrm{H} / \mathrm{SiO}_{2}}=10^{-4} \exp (-0.18 \mathrm{eV} / k T) \text {. }
$$

При комнатной температуре его значение составляет $\sim 9.5 \cdot 10^{-8} \mathrm{~cm}^{2} / \mathrm{c}$. При времени окисления 5-10 мин диффузионная длина атомарного водорода составляет $\sim 5 \cdot 10^{-3} \mathrm{~cm}$, т.е. на 3-4 порядка величины больше, чем толщина растущего слоя $\mathrm{SiO}_{2}$. Однако атомарный водород в оксиде кремния не является долгоживущей формой его существования. Он взаимодействует либо с присутствующими в окисле радикалами, либо образует молекулу $\mathrm{H}_{2}[11]$.

Коэффициент диффузии молекулярного водорода в $\mathrm{SiO}_{2}$ как функция температуры имеет вид [12]

$$
D_{\mathrm{H}_{2} / \mathrm{SiO}_{2}}=5.65 \cdot 10^{-4} \exp (-0.45 \mathrm{eV} / k T)
$$

При комнатной температуре его величина равна $\sim 1.5 \cdot 10^{-11} \mathrm{~cm}^{2} / \mathrm{c}$. Это соответствует при временах окисления диффузионной длине $\sim 7 \cdot 10^{-5}$ см, что также на порядок величины больше толщины слоя $\mathrm{SiO}_{2}$, выращиваемого в процессе анодного окисления. Иными словами, диффузия водорода к микропорам в кремнии может осуществляться через слой растущего окисла.

Заполнение микропор водородом, поступающим извне, приводит к росту в них давления водородного газа и росту размеров пузыря. Критический размер пузыря зависит как от концентрации водорода, так и от глубины залегания микропоры [10]. Зная геометрические размеры пузыря, можно оценить концентрацию молекул водорода в нем. Выражение, связывающее размеры пузыря и количество молекул водорода в нем в случае, когда радиус пузыря много больше расстояния до поверхности образца, было получено в работе [10]:

$$
h=\left(N A k T / r_{0}\right)^{1 / 2},
$$

где $h$ - высота пузыря, $r_{0}-$ радиус пузыря, $A=\left(1-v^{2}\right) / E, \quad v-$ коэффициент Пуассона, для кремния $v=0.42, E-$ модуль Юнга, для кремния $E=1.66 \cdot 10^{12}$ дин $/ \mathrm{cm}^{2} ; k-$ постоянная Больцмана, $T-$ температура. При среднем размере основания пузыря на поверхности слоя КНИ 20 мкм и высоте $\sim 1$ мкм количество молекул водорода в нем составляет $\sim 10^{15}$ штук. При средней плотности пузырей на поверхности $\sim 10^{3} \mathrm{~cm}^{-2}$ это соответствует концентрации молекул водорода $10^{18} \mathrm{~cm}^{-2}$, что в 37 раз превышает полную дозу имплантированного молекулярного водорода. Таким образом, оценки показывают, что рост водородного пузыря происходит в основном за счет водорода, поступающего не из имплантированного слоя, а извне.

Зарождение водородных пузырей на поверхности, повидимому, является причиной низкой скорости окисления верхнего приповерхностного слоя при температурах 
ниже $1100^{\circ} \mathrm{C}$ (рис. 2). Действительно, последовательное окисление и стравливание верхнего нарушенного слоя приводит к удалению центров зарождения водородных пузырей и увеличению скорости окисления. Интересно, что сами по себе радиационные дефекты не снижают, а скорее увеличивают скорость зарождения фазы $\mathrm{SiO}_{2}$ на поверхности кремния. В работе [13] указывается на то, что на поверхности кремния, облученной ионами средних энергий, слой оксида кремния при анодном окислении растет более равномерно, чем на необлученной поверхности. Поэтому роль радиационных дефектов в слоях кремния, имплантированных ионами водорода, по-видимому, связана с формированием вакансионных микропор, которые являются стоком для водорода, поступающего извне.

Изменение скорости анодного окисления в зависимости от температуры отжига и глубины слоя кремния (рис. 2 и 3) указывает на то, что ее значение определяется как наличием структурных нарушений (микропор), так и концентрацией водорода в слое КНИ. Увеличение температуры отжига приводит, с одной стороны, к отжигу дефектов и уменьшению сопротивления окисляемого слоя; это в свою очередь может приводить к увеличению скорости роста анодного окисла. С другой стороны, скорость окисления увеличивается с глубиной и имеет обратную зависимость от концентрации водорода в пленке. Это указывает на то, что наличие водорода в пленке препятствует реакции взаимодействия кислорода и кремния. Уменьшение концентрации имплантированного водорода на один порядок величины приводит к росту скорости окисления в 3 раза. Следует заметить, что наклон кривых на рис. 3 практически одинаков для всех температур отжига в интервале $700-1000^{\circ} \mathrm{C}$. Этот эффект требует дальнейшего более подробного изучения.

\section{4. Заключение}

Изучен процесс анодного окисления пленок кремнийна-изоляторе, созданных методом водородного переноса. Обнаружено, что скорость анодного окисления перенесенных пленок в $\sim 5$ раз меньше скорости окисления образцов монокристаллического объемного кремния. С ростом температуры отжига скорость окисления пленок увеличивается и при температуре $1100^{\circ} \mathrm{C}$ становится близкой к скорости окисления монокристаллического $\mathrm{Si}$. Скорость окисления пленок КНИ увеличивается с глубиной по мере поэтапного удаления анодно-окисленных слоев. Наклон зависимости скорости анодного окисления от толщины удаленного слоя кремния на глубинах $\gtrsim 50$ нм не зависит от температуры отжига в интервале $700-1000^{\circ} \mathrm{C}$. Полученные результаты объясняются отжигом дефектов и выходом водорода из связанного состояния, что приводит к увеличению эффективности анодного тока и ускоряет взаимодействие атомов кислорода и кремния соответственно. Обнаружен рост водородных пузырей на поверхности пленки кремния за счет диффузии водорода, высвобождающегося в процессе реакции окисления, к вакансионным микропорам в имплантированном слое КНИ.

Авторы выражают благодарность сотрудникам технологического участка КНИ и КНС структур ИФП СО РАН, В.А. Антонову за помощь при анализе поверхности образцов, В.П. Попову за полезные обсуждения результатов.

\section{Список литературы}

[1] P.F. Schmidt, W. Michel. J. Electrochem. Soc., 104, 230 (1957).

[2] K.M. Busen, R. Linsey. Trans. Metall. Soc. AIME., 236, 306 (1966).

[3] W. Przyborski, J. Roed, J. Lippert, L. Sarholt-Kristensen. Radiat. Eff., 1, 33 (1969).

[4] N.G.E. Johannson, I.W. Meyer. Solid-State Electron., 13, 317 (1970).

[5] A. Manara, A. Ostidich, G. Pedroli, G. Restelli. Thin Sol. Films, 8, 359 (1971).

[6] В.А. Антонов, Е.В. Спесивцев, И.Е. Тысченко. ФТП, 45, 1121 (2011).

[7] G. Mende, G. Küster. Thin Sol. Films, 35, 215220 (1976).

[8] В.П. Попов, И.Е. Тысченко. Патент РФ № 2217842 (Бюл. № 33, 27.11. 2003).

[9] J.P. Biersack, L. Haggmark. Nucl. Instrum. Meth., 174, 257 (1980); www.srim.org

[10] K. Mitani, U.M. Gösele. Appl. Phys. A, 54, 543 (1992).

[11] D.L. Griscom. J. Appl. Phys., 58, 2524 (1985).

[12] D.L. Griscom. J. Non-Cryst. Sol., 68, 301 (1984).

[13] Н.Н. Герасименко, А.В. Двуреченский, Г.М. Цейтлин. ПТЭ, 5, 254 (1972).

\section{Редактор Л.В. Шаронова}

\section{Anodic oxidation of hydrogen-transferred silicon-on-insulator layers}

\section{I.E. Tyschenko, I.V. Popov, E.V. Spesivtsev}

Rzhanov Institute of Semiconductor Physics, Siberian Branch of Russian Academin of Sciences, 630090 Novosibirsk, Russia

\footnotetext{
Abstract The anodic oxidation rate of hydrogen-transferred silicon-on-insulator films as a function of subsequent annealing temperature as well as the depth from the top silicon surface was studied. It was obtained that the oxidation rate of the as-transferred SOI (silocon-on-insulator) films is lower by the factor of 5 than that of monocrystalline bulk silicon. The anodic oxidation rate grew both as the annealing temperature increased within the range $700-1100^{\circ} \mathrm{C}$ and as step-by-step removing anodic oxidizing layers. The obtained results were explained by an increase in the anodic current efficiency and by the increasing interaction of oxygen and silicon atoms during defect annealing and hydrogen leaving the bound state respectively. The formation of hydrogen bubbles on the silicon surface by external hydrogen diffusion produced as a result of oxidation reaction was obtained.
} 